Article

\title{
Understanding Adaptation Finance Allocation: Which Factors Enable or Constrain Vulnerable Countries to Access Funding?
}

\author{
Deepal Doshi *(D) and Matthias Garschagen $(\mathbb{D}$ \\ Department of Geography, Ludwig-Maximilian-University Munich, 80333 Munich, Germany; \\ m.garschagen@lmu.de \\ * Correspondence: deepal.doshi@lmu.de
}

Received: 3 April 2020; Accepted: 19 May 2020; Published: 25 May 2020

check for updates

\begin{abstract}
The most vulnerable countries often face a double burden in relation to climate change-they are at high risk to the impacts and are least equipped to cope and adapt. Global climate policy since the Convention in 1992, until most recently with the global goal on adaptation in the Paris Agreement, has manifested the importance of prioritizing adaptation support to the most vulnerable countries. The main objective of this study is to understand the enabling and constraining factors that play a role in the process of allocating and accessing global adaptation assistance. We adopted a mixed-methods approach combining two major streams of analysis. First, this paper aims to track bilateral adaptation finance to all so-called developing countries, as bilateral support has been the largest share of international adaptation finance. Second, the paper draws on semi-structured expert interviews and looks at the country level to identify the factors beyond vulnerability that play a role in the distribution of adaptation finance from a recipient's and a donor's perspective, using India and Germany as examples. The analysis yields three main findings. First, countries' vulnerability as measured by standard metrics does not seem to be the prime factor explaining the distribution of available bilateral adaptation assistance. This is in contrast to the political narrative in the emerging climate finance architecture. Second, interview data identified other factors beyond vulnerability that play a role from a donor perspective, such as the perceived capacity to manage and implement projects, the commitment given to climate change and other political priorities. Third, from a recipient perspective, rather than its vulnerability level in a global comparison, strong institutional capacity played a prominent role in attracting adaptation finance. Looking out into the future, the findings underscore the practical and political challenges in relation to a vulnerability-oriented prioritization of funding and they point towards the need to increase countries' capacities to attract and manage international adaptation support. The findings also raise questions on how to overcome the vexing conflict in the emerging adaptation finance architecture between accommodating for donors' requirements of high fiduciary standards and enabling access by the most vulnerable countries, which are often short of resources and institutional capacities.
\end{abstract}

Keywords: tracking adaptation finance; vulnerability; bilateral aid; Germany; India

\section{Introduction}

The adoption of the Paris Climate Agreement (PA) in December 2015 marked a landmark achievement for the adaptation pillar of international climate policy. Countries jointly recognized and encoded the global goal on adaptation "of enhancing adaptive capacity, strengthening resilience and reducing vulnerability to climate change" [1] (Article 7, p. 6). The Agreement also recognizes the need for adaptation support and stipulates the goal to prioritize the needs of developing countries, particularly 
those with the highest vulnerability to climate change impacts (Article 7, p. 6). Yet, the Adaptation Finance Gap Report [2] notes that adaptation finance is "a means rather than an end" (p. xii) and that simply increasing the availability of funds is not enough to ensure the efficiency and effectiveness in reducing vulnerability. Rather, the report calls for increased efforts to track adaptation finance flows to ensure that "it is being targeted where it is most needed" (p. xiii). The question, therefore, becomes whether the most vulnerable countries are and have been prioritized in adaptation finance- - the entry point into the study presented here. One of the central challenges in this question revolves around the definition, measurement, and ranking of vulnerability, which is a scientific as well as a political challenge, not least from a donor perspective [3,4]. However, the distribution of adaptation assistance depends not only on perceived levels of vulnerability and donor countries' allocations but also on the capacities of recipient countries to access, manage, and implement this support. Hence, an additional question becomes: Which enabling and constraining factors beyond vulnerability exist that play a role in donor countries' allocations and recipient countries' access to adaptation finance?

Adaptation finance is of increasing importance to the most vulnerable countries because they face a double burden in relation to climate change [5]. In many cases, they do not only have the least capacities and resources to cope and adapt but also face the worst impacts. The moral obligation of developed countries to financially support the most vulnerable countries to adapt to climate change comes out of historical developments in climate policy and the acknowledgement of a perceived injustice towards developing countries. It has led to the principle of "common but differentiated responsibility and respective capabilities", according to which developed countries are to provide financial resources to assist developing countries in implementing the climate change mitigation and adaptation objectives of the United Nations Framework Convention on Climate Change (UNFCCC). This principle has been codified in the logic and language of the Convention (UNFCCC, 1992) [6] and reiterated in several Conferences of the Parties (COPs), especially in Bali, Copenhagen [7,8] Cancun [9], and Durban, which marked significant developments in the international architecture of adaptation finance. The most recent reiteration of this commitment was made in the Paris Agreement, in Article 9 that calls on developed countries to financially assist developing countries, "especially those that are particularly vulnerable to the adverse effects of climate change and have significant capacity constraints" [1] (Article 9, p. 13).

In order to implement the moral obligation and political commitment to prioritize adaptation support for the most vulnerable, it is important to track adaptation finance and ensure its efficiency and effectiveness [2]. In the international architecture of adaptation finance, public resources flow through two channels, bilateral and multilateral. In this paper, we emphasize the bilateral channel, which is by far the largest source of adaptation support for developing countries. A breakdown of the total Overseas Development Assistance (ODA) commitments to adaptation from 2010 to 2015 shows that $69 \%$ was allocated by donors bilaterally, $7 \%$ multilaterally, and $24 \%$ by Multilateral Development Banks [10-15]. In the multilateral channel, significantly emerging sources include dedicated funds-based mechanisms such as the Green Climate Fund (GCF) and the Adaptation Fund. A detailed analysis tracking the flows of adaptation-related funding from the GCF reveals that adaptation finance is not only distributed based on vulnerability considerations [16]. However, whether this picture also remains true for bilateral adaptation assistance-the largest chunk-remains open. Open also is the question of what other factors explain the distribution of adaptation finance from a donor and a recipient perspective if vulnerability is not the only or primary explanatory factor.

This paper contributes to responding to these questions. First, it reviews and assesses the existing scholarship on tracking bilateral adaptation finance to vulnerable countries (see Question 1 below). In a second step, it aims to track bilateral ODA commitments targeted at adaptation to assess to what extent the most vulnerable countries are prioritized (Question 2).

In a third step, it draws on the cases of Germany and India to analyze in more detail the funding allocation of Germany (Question 3) and the factors beyond vulnerability that play a role in the distribution of adaptation finance from a donor and a recipient perspective (Questions 4 and 5). 
Germany is a key actor in the international climate finance landscape, being one of the largest providers of bilateral finance. India was the top recipient of bilateral climate finance in 2016 and 2017 [11] and was among the top five countries most affected by climate change in 2018, according to the Climate Risk Index released at COP 25 [17].

In detail, this paper addresses five key questions:

Q1. What does the literature tell us about the current state of conceptual and empirical knowledge on adaptation finance flows to the most vulnerable countries?

Q2. Is bilateral adaptation assistance on a global scale flowing to the most vulnerable countries as prioritized in the Paris Climate Agreement?

Q3. Is Germany's bilateral adaptation assistance flowing to the most vulnerable countries as prioritized in the Paris Climate Agreement?

Q4. Which factors beyond vulnerability play a role in the allocation of Germany's bilateral adaptation finance from a donor perspective?

Q5. Which factors beyond vulnerability play a role in India's receipt of bilateral adaptation finance from a recipient perspective?

The paper is structured in four sections. Section 2 lays out and discusses the overall research design and the different methods and data used for answering the paper's five questions. Section 3 presents the results structured along the five questions. Hence, Section 3.1 draws on literature to assess the current state of conceptual and empirical knowledge of adaptation finance flows to the most vulnerable countries (Q1). Section 3.2 presents the results of the quantitative tracking of bilateral adaptation assistance, more specifically, its correlation to countries' vulnerability metrics at the global scale (Q2), followed by Section 3.3, which presents the respective findings for Germany's bilateral adaptation assistance (Q3). Both sections show that the distribution of neither global nor German bilateral adaptation assistance can exclusively—or even chiefly—be explained by the recipient country's level of vulnerability as measured with widely used global indices. At the same time comprehensive quantitative data to test other potential factors by means of a regression analysis are not available. Sections 3.4 and 3.5 therefore draw on expert interview data and present qualitative findings regarding other factors beyond vulnerability that play a role in allocating and accessing funding. In doing so, Section 3.4 dives deeper into a donor's perspective, using the example of Germany's allocation considerations (Q4), while Section 3.5 focuses on recipient perspectives, using the example of India's access to adaptation finance (Q5). Section 4 draws key conclusions from the analysis, also considering the study's limitations, and discusses implications for further research, policy, and practice.

\section{Methods and Data}

This study adopted a mixed-methods research design, combining three major methods: a literature review, a statistical correlation analysis, and the analysis of qualitative expert interview data to answer the five research questions stated above.

\subsection{Literature Review}

In order to respond to the first question, the paper provides a review of previous literature on the tracking and allocation of adaptation finance (Q1). The review is neither structured nor exhaustive but focuses on key studies to inform the hypotheses and research design of the remaining study.

\subsection{Correlation Analysis: Bilateral Adaptation Assistance and Vulnerability}

The second aim of the study is to test whether and to what extent the scientific and political goal to prioritize adaptation finance to the most vulnerable countries has been implemented. For this we performed statistical analyses of how far a country's amount of received bilateral adaptation finance is correlated to its level of vulnerability. We first did this with all bilateral adaptation finance allocated globally (Q2) and then specifically with the finance allocated by Germany (Q3). 
At the global level (Q2), we conducted a bivariate correlation between bilateral adaptation finance flows and vulnerability levels of all developing countries $(n=154)$ according to standard vulnerability metrics. The bivariate correlation analysis hence in principle comprised two variables: bilateral adaptation assistance amounts and vulnerability levels of developing countries. In the analysis we considered and compared the finance flows over the two time frames of 2010-2015, i.e., pre-Paris Agreement, and 2016-2017, i.e., post-Paris Agreement. The aim of this comparison was to test whether the commitments of the Paris Agreement (see Section 1) have had a measurable effect on the allocation of adaptation assistance - yet acknowledging that only two years of coherent data were available for the post-Paris Agreement time frame and hence our observations can only be indicative at this point as they might not fully capture delays in allocation adjustments. In the correlation analysis, we also compared the strength of the correlations when using absolute assistance amounts as compared to those adjusted for GDP per capita. We used the latter in order to control for the size of the respective economy as well as the pricing level within it as a proxy for the purchasing power of the financial assistance attributed. The sample of 154 developing countries selected for this analysis referred to the Non-Annex I country Parties to the Paris Agreement, retrieved from the UNFCCC List of Parties [18]. Bilateral adaptation assistance data were taken from the OECD Rio Marker database and counted all Principal and Significant adaptation activities committed over 2010-2017 (time frame before and after the Paris Agreement until which data are available) [19]. The Rio Adaptation Marker was introduced in 2010 after the COP in Cancun and revised in 2016 [2,20]. This database is the single largest comprehensive and openly accessible source of adaptation finance flows on an international level, allowing for data comparability.

However, there are challenges related to this data that need to be considered when reflecting the methodological limits of our approach [21-25]. Although the introduction of the OECD Rio Marker on adaptation in 2010 marked significant progress in tracking efforts towards adaptation finance $[2,19]$, concerns have been raised on the reliability of the dataset. These include having an inconsistent provider-coded approach, reporting in commitment instead of disbursement figures, and, most importantly, gross overestimations in reporting climate-related finance by "over-coding" [21-25]. The implications of the lack of reliability on this data are serious when considering that countries often use it in reporting their commitments to the UNFCCC and stating their contributions at COPs [25]. However, efforts are being made to improve the system. In April 2016, OECD revised the definition of the marker and included additional support such as guidance tables, eligibility criteria for different sectors, and detailed guidelines on the use of the marker, potentially further improving the quality of the data in the future.

For operationalizing vulnerability levels of developing countries, this study uses mean vulnerability scores of countries across the dedicated vulnerability modules of the three most widely used and cited global risk indices, namely, the World Risk Index [26], Notre Dame-Global Adaptation Index (ND-GAIN) [27], and the Index for Risk Management (INFORM) [28]. These indices are built in a modular way and comprise different sub-components such as hazard, vulnerability, etc. As this study focuses on vulnerability, we use the vulnerability module or sub-index scores of the respective indices. Given the time frames considered in our analysis (pre- and post-Paris Agreement) we use the index data of 2015. The vulnerability metrics of these three indices show a strong positive correlation. The correlation value between vulnerability metrics of the World Risk Index and INFORM is 0.813 . Between the World Risk Index and ND-GAIN it is 0.864 and between INFORM and ND-GAIN it is 0.720. Each correlation is significant at the level of $p \leq 0.01$ (2-tailed). For our correlation analysis, we calculated and used the mean vulnerability across the three indices. In order to account for the slightly different number of countries covered in the three indices and for our sub-set of 154 countries, we extracted these 154 countries from the global data-sets, ranked them according to their vulnerability scores and then normalized the data using the Min-Max method on a scale from 0 (country with the lowest vulnerability) to 1 (country with the highest vulnerability). Following this step, we calculated the mean vulnerability value for each country. In the case of missing values in one or two of the indices, 
the available score was weighted three or two times, respectively, to accommodate the missing data. For four countries-Andorra, Cook Islands, Niue, and San Marino-the vulnerability data were not available in any of the three indices. These countries were thus excluded from the analysis.

However, this data and the underlying operationalization of vulnerability is not without problems, which were discussed in the literature and need to be reflected in the context of the limitations of our approach. Vulnerability is multidimensional, context-specific, scale-dependent, often latent in nature, and hence very difficult to measure at the country level. Epistemological, ontological, and methodological challenges around measuring vulnerability therefore include, but are not limited to, aspects of indicator validity, scales, weighting, ranking, and quantifying many key dimensions of vulnerability $[4,29]$. This makes the use of a single vulnerability measure problematic, as each such measure represents a particular set of considerations and could lead to different results. At the same time, index-based approaches for assessing country-level vulnerability have gained a lot of traction at the global stage as they are widely seen to provide the best possible comparative information. They can be important to informing global policy, for example, in relation to the programming of risk reduction, the prioritization of funding, or tracking of progress towards the reduction of vulnerability [29,30], e.g., within the Framework of the Global Stocktake under the Paris Climate Agreement, the Sustainable Development Goals, or the Sendai Framework for Disaster Risk Reduction. Acknowledging these limitations but also recognizing that global vulnerability metrics have grown to take a prominent role in international policy forums and debates, we used the mean vulnerability score for each country across the three indices to overcome the existing challenges at least as much as possible and to increase the study's robustness.

At the national level (Q3), for tracking Germany's bilateral adaptation finance flows, we followed the same method as for the global analysis and conducted a bivariate correlation between Germany's bilateral adaptation assistance over 2011-2015 (pre-Paris) and 2016-2017 (post-Paris) with vulnerability levels of all developing countries $(n=154)$. We used the German Climate Finance Database (Datenbank Deutsche Klimafinanzierung) [31] for adaptation funding data from 2011 to 2015 (pre-Paris timeframe). The methodology of the German Climate Finance Database differs slightly from that of the OECD Rio Markers and counts $100 \%$ of the amount as adaptation when it is a "principal" objective and $50 \%$ of the amount when it is a "significant" objective. The comparison of the finance figures across both time spans has therefore to be taken with care. For the post-Paris timeframe, more recent data were available from the OECD Rio Marker database for 2016 and 2017.

\subsection{Expert Interviews: Other Factors Shaping Finance Allocation and Access}

In addressing Q4 and Q5 we conducted semi-structured expert interviews in order to explore factors beyond vulnerability that play a significant role in the allocation and access of adaptation finance. This was because the results of the correlation analysis showed that vulnerability alone could not explain the observed funding allocation and, hence, other factors were at work. Yet, comprehensive quantitative data to run a regression analysis were not available and potential factors to be included into a model were not known. Therefore, we conducted 19 semi-structured expert interviews with stakeholders from Germany and India to explore in more detail the factors beyond vulnerability from the donor and recipient perspectives and from the bottom-up. We identified key organizations in both countries, including government ministries, national implementing entities of adaptation projects, civil society organizations, NGOs, and international organizations (see Table A1 in the Appendix A for an overview of interviewees' organizations and an explanation of the abbreviations for the interviews used in the paper).

The rationale for using semi-structured interviews stems from two objectives: first, such interviews are suited for efficiently acquiring insights from experts who were senior officers or chief managers in the ministries and had limited time; second, semi-structured interviews were highly suited to this study as they allowed us to capitalize their "freewheeling quality" [32] whilst also accommodating a prepared guide of questions and facilitating some degree of comparability. The transcribed interviews and notes 
were coded with a combination of both inductive and deductive codes. Results were then analyzed using a grounded theory approach developed by Glaser and Strauss (1967) [33], which allowed for an open, explorative approach to the identification of themes and patterns within the data [32,34].

\section{Results}

\subsection{Literature Review: Current State of Conceptual and Empirical Knowledge on Adaptation Finance Allocation and Access}

Studying the allocation of bilateral climate finance is a relatively new field of research but it has been growing in comparison to literature on the allocation of development aid, in which scholars have engaged for decades. Development aid allocation models introduced in the 1970s-1990s almost exclusively applied a donor perspective and categorized allocation factors into three categories relating to "recipient need," "donor interest," and "recipient merit" [35-39]. The recipient need model is based on the argument that donors provide economic assistance for altruistic reasons to support poor countries. The donor interest model argues that aid is provided to fulfill donors' own economic and political interests. A third model introduced in the 1990s added the dimension of "recipient merit," implying that countries with "good governance" would ensure that aid be used more effectively $[38,39]$. These models have also been adapted in analyses of the allocation of environmental or "green" aid [40-42]. Correlation and regression analyses were conducted in studies on green or environmental aid to test the determinants of allocation [43]. These studies are useful in understanding the determinants of aid allocation. However, the findings cannot be directly transferred to adaptation finance, and a comparison of aid allocation patterns between development aid, green aid, and adaptation finance is beyond the scope of this study. Yet the concepts of recipient need, donor interest, and recipient merit are useful in guiding the analysis of this paper, i.e., the analysis of factors that might explain the allocation of bilateral adaptation finance. Studies on the allocation of bilateral climate adaptation finance have used the determinants of development aid allocation-recipient need, recipient merit, and donor interest for their analysis [44-47]. However, whether these earlier models can be transferred from the context of development aid to the context of climate change finance remains open [48] — which is one of the interests of this study.

The literature review also shows that while the need to prioritize the most vulnerable countries in the allocation of adaptation finance is emphasized in scientific and political spheres, both communities are confronted with challenges in operationalizing and implementing this goal. The scientific community is faced with two main challenges: the ontological challenge of defining vulnerability conceptually and the methodological challenge of measuring it in an objective way (cf. Section 2.2) [29,49]. In terms of conceptual definitions, a large number of alternative suggestions can be found in the literature, oftentimes representing quite opposing conceptions [30,50-52]. Klein and Möhner (2011) [4] concluded that it is not possible to attach an "objectivist truth" to measuring vulnerability and that "any agreed approach will have to be the socially constructed outcome of a negotiation process" (p. 16).

The lack of a scientific consensus on conceptually defining and measuring vulnerability is reflected in policy as well. Policymakers are also confronted with the challenge of operationalizing vulnerability. Looking at climate policy negotiations over time, from the Convention in 1992 to this date, there has been no agreed methodology on how to prioritize the "particularly vulnerable" for the allocation of adaptation finance. Choosing a single vulnerability index and prioritizing funding on that basis is tricky because different indices can produce different results. Although there have been efforts to specify examples of groups of countries (e.g., LDCs, SIDS, and African countries within the Green Climate Fund), no agreement has been reached on a threshold to distinguish the "most vulnerable" from the vulnerable because this would have significant financial implications for prioritization in the allocation of adaptation finance. This was seen during policy negotiations, where developing countries were observed to compete for the designation as the most vulnerable, a process that Khan even compared to a "beauty contest" (CAN International, 1 December 2010, as cited in [53]). Hence, 
these challenges make it difficult for policymakers to objectively prioritize the allocation of adaptation finance to the most vulnerable, resulting in an unsystematic approach fraught with ambiguity.

Previous studies on the allocation of bilateral adaptation finance that used development aid allocation models argued that donors do take into account vulnerability (or "recipient need") of a recipient country [44-46]. However, a closer look at the variables used to support the above argument shows that physical vulnerability or exposure played a stronger role than socioeconomic vulnerability $[46,47,51,52]$. Although countries belonging to vulnerable groups in the international climate debate (such as LDCs, SIDS, and African States) were found to receive high volumes of bilateral adaptation finance per capita, previous regression analysis using selected singular vulnerability metrics suggested that the status of belonging to such a group does not play a role in receiving these high amounts [45]. Other studies [46] at the sub-national [54], national [44,55], and regional [56] scales confirmed the findings observed at the global scale. Physical exposure seems to be a stronger predictor for receiving bilateral adaptation finance than socioeconomic dimensions of vulnerability [45]. Other factors such as language, trade relations, pre-existing ODA activity, population size, and GDP per capita were also found to play a role $[45,56,57]$.

Previous analyses on the allocation of multilateral funds, such as the Adaptation Fund (AF) and Green Climate Fund (GCF) showed that, rather than vulnerability, there may be other factors at play that offer a stronger explanation. For the case of the AF, Persson and Remling (2014) [58] argued that it rather tends to an equality approach by placing an equal fund ceiling or country cap of USD 10 million for all eligible developing countries. Stadelmann et al. (2014) [59] confirmed the weak role of vulnerability in allocation decisions of the AF and argue on the contrary that absolute economic savings of projects offer a stronger explanation. Garschagen and Doshi's analysis of adaptation-related funding of the GCF showed that allocation so far shows an ambiguous picture (under review) [16]. On one hand, the GCF is on track in prioritizing the most vulnerable countries according to its prioritization in terms of country groups, namely LDCs, SIDs and African countries. On the other hand, the complex application process poses significant capacity challenges to many countries with the highest climate vulnerability, which may have weak institutions and fragile state bureaucracies.

Against this background, our study contributes to the literature in two ways. Empirically, the study does not only consider a donor perspective-as most of the existing studies do-but juxtaposes it with original empirical insight from a recipient perspective. Hence the study adds to the literature by analyzing recipient views on accessing funding. Second, methodologically, the study goes beyond quantitative approaches and adopts a mixed-methods design. Drawing on rich qualitative data, it aims to understand in depth the enabling and constraining factors that play a role in the allocation of and access to adaptation finance.

\subsection{Correlation Analysis: Vulnerability and Bilateral Adaptation Assistance at the Global Scale}

The bivariate correlation analysis conducted between the variables bilateral adaptation assistance (in absolute terms and adjusted for GDP per capita) and mean vulnerability tested the following hypothesis: The higher the vulnerability, the more adaptation assistance the recipient country receives.

The findings presented in Table 1 and Figure 1 show that, in principle, a correlation between a country's level of vulnerability and its funding acquisition can be observed but that the correlation is weak, meaning that other factors are at play and probably even more important. The analysis presented here is for the time periods of 2010-2015, i.e., pre-Paris Agreement, and 2016 and 2017, i.e., post-Paris. 
Table 1. Correlation results showing the relationship between countries' mean vulnerability and average annual amounts of bilateral adaptation assistance allocated by all global sources from 2010 to 2015 and from 2016 to 2017 in both absolute amounts and adjusted for GDP per capita. * Correlation is significant at the 0.05 level (2-tailed). ${ }^{* *}$ Correlation is significant at the 0.01 level (2-tailed).

\begin{tabular}{ccccc}
\hline & $\begin{array}{c}\text { Amount AVG } \\
\mathbf{2 0 1 0 - 2 0 1 5} \\
\text { (Absolute) }\end{array}$ & $\begin{array}{c}\text { Amount AVG } \\
\text { 2010-2015 } \\
\text { (GDP Per } \\
\text { Capita) }\end{array}$ & $\begin{array}{c}\text { Amount AVG } \\
\text { 2016-2017 } \\
\text { (Absolute) }\end{array}$ & $\begin{array}{c}\text { Amount AVG } \\
\text { Per Capita) }\end{array}$ \\
\hline $\begin{array}{c}\text { Mean vulnerability } \\
\text { N }\end{array}$ & $0.200^{*}$ & $0.413^{* *}$ & $0.269^{* *}$ & $0.483^{* *}$ \\
154 & 150 & 154 & 150 \\
\hline
\end{tabular}
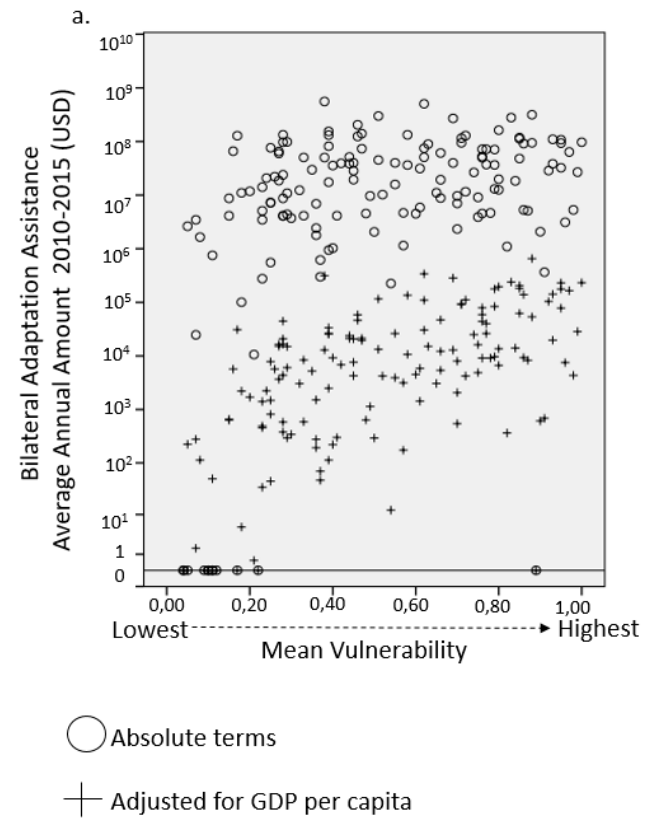

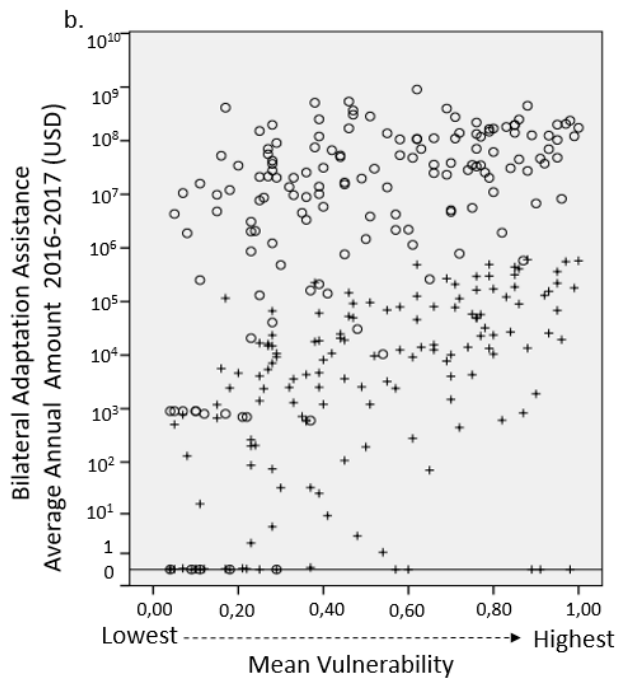

Mean Vulnerability

Figure 1. Scatterplots showing the relationship between countries' mean vulnerability and average annual amounts of bilateral adaptation assistance allocated by all sources globally in both absolute terms and adjusted for GDP per capita and for two time frames: (a) 2010-2015 corresponding to pre-Paris Agreement and (b) 2016-2017 corresponding to post- Paris Agreement.

Table 1 shows that very weak to weak correlations can be observed $(0.200 *$ to $0.483 * *)$ in both timeframes, pre- and post-Paris Agreement. The scatterplots in Figure 1 provide a more detailed picture by illustrating the distribution of adaptation assistance in absolute amounts and adjusted for GDP per capita for both time frames, pre-Paris Agreement from 2010 to 2015 (Figure 1a) and post-Paris Agreement from 2016 to 2017 (Figure 1b). According to the hypothesis, had the most vulnerable countries been prioritized, there would be a much clearer pattern visible in the scatterplots. This is not the case. The low correlation values in combination with the distributed scatterplots hence suggest that other factors beyond vulnerability play a significant role in the distribution of bilateral adaptation assistance at the global scale.

\subsection{Correlation Analysis: Vulnerability and Bilateral Adaptation Assistance Allocated by Germany}

The second step of the analysis on the national level (Q3) tracked the flows of Germany's bilateral ODA commitments to adaptation over 2011-2015, i.e., pre-Paris Agreement, and 2016-2017, i.e., post-Paris Agreement. The bivariate correlation analysis was between the same variables as for the global level: recipient countries' mean vulnerability and allocated adaptation assistance. The only difference was that in this case the analysis considered only countries that received adaptation assistance 
from Germany. Hence, the hypothesis remained similar to the one for the global level: The higher the vulnerability, the more adaptation assistance the recipient country receives from Germany.

The findings presented in Table 2 and Figure 2 show that, in principle, a weak correlation between a recipient country's level of vulnerability and its funding acquisition can be observed, indicating that there are other factors at play and perhaps even more important. The findings are similar to the patterns seen in the global picture, insofar as they also show a weak correlation, however, with the values at the national level even weaker and less/not significant in comparison to the global level.

Table 2. Correlation results showing the relationship between countries' mean vulnerability and average annual amounts of bilateral adaptation assistance allocated by Germany from 2011 to 2015 and from 2016 to 2017 in both absolute amounts and adjusted for GDP per capita. * Correlation is significant at the 0.05 level (2-tailed). ${ }^{* *}$ Correlation is significant at the 0.01 level (2-tailed).

\begin{tabular}{ccccc}
\hline & $\begin{array}{c}\text { Amount AVG } \\
\text { 2011-2015 } \\
\text { (Absolute) }\end{array}$ & $\begin{array}{c}\text { Amount AVG } \\
\text { 2011-2015 } \\
\text { (GDP Per } \\
\text { Capita) }\end{array}$ & $\begin{array}{c}\text { Amount AVG } \\
\text { 2016-2017 } \\
\text { (Absolute) }\end{array}$ & $\begin{array}{c}\text { Amo16-2017 (GDP } \\
\text { Per Capita) }\end{array}$ \\
\hline $\begin{array}{c}\text { Mean vulnerability } \\
\text { N }\end{array}$ & $0.171^{*}$ & $0.442^{* *}$ & 0.083 & $0.418^{* *}$ \\
150 & 150 & 150 & 150 \\
\hline
\end{tabular}
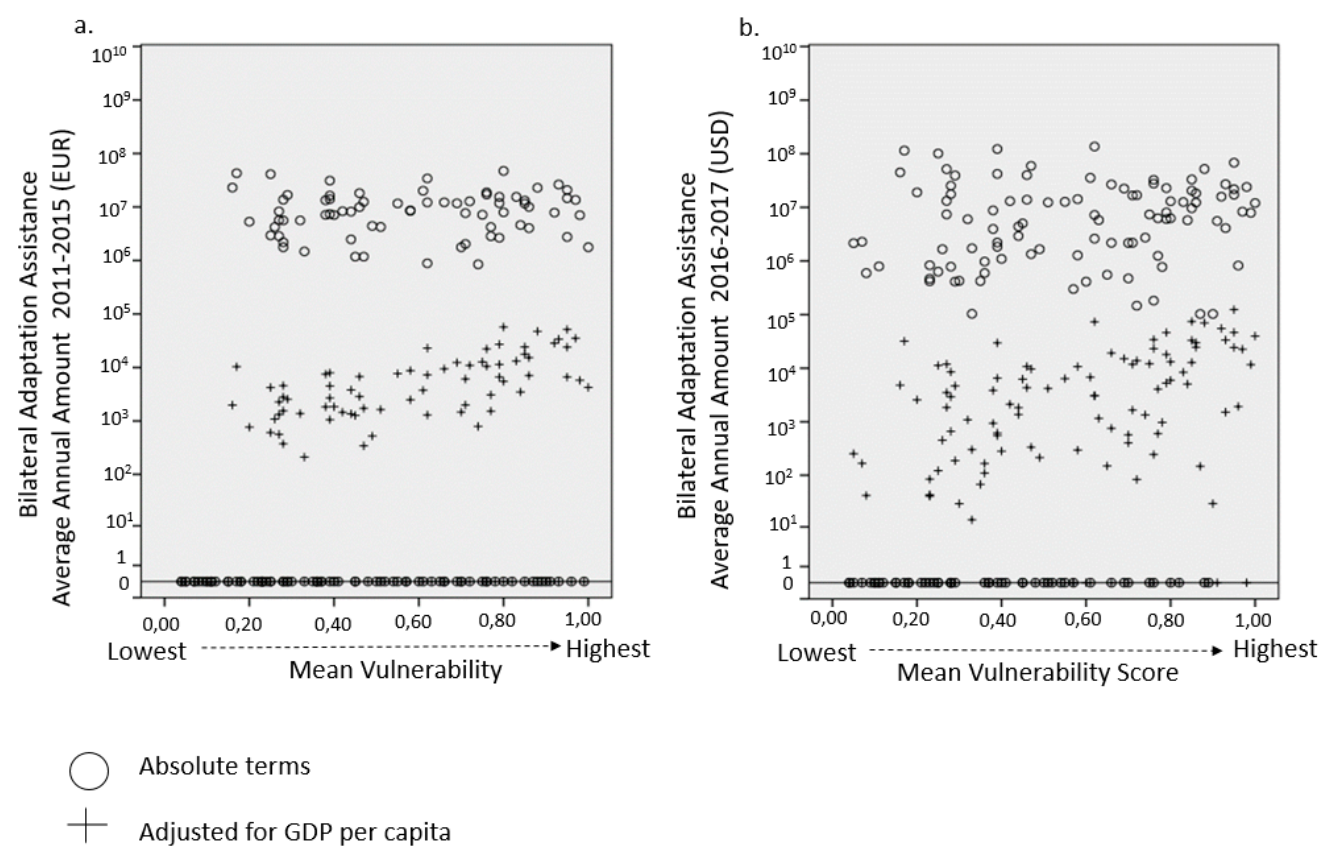

Figure 2. Scatterplots showing the relationship between countries' mean vulnerability and average annual amounts of bilateral adaptation assistance allocated by Germany in both absolute terms and adjusted for GDP per capita and for two time frames: (a) 2011-2015 corresponding to pre-Paris Agreement and (b) 2016-2017 corresponding to post- Paris Agreement.

Table 2 shows that non-significant to weak correlations can be observed $\left(0.083\right.$ to $\left.0.442{ }^{* *}\right)$. The scatterplots in Figure 2 provide a more detailed picture by illustrating the distribution of Germany's bilateral adaptation assistance in absolute amounts and adjusted for GDP per capita for both time frames: pre-Paris Agreement and post-Paris Agreement, respectively (Figure 2a,b). According to the hypothesis, had there been a strict prioritization of the most vulnerable countries, there would be a clear upward pattern visible in the scatterplots (Figure 2). As the scatterplots suggest, this is clearest in the case for adaptation amounts adjusted for GDP per capita post-Paris over 2016-2017. Yet overall, the low correlation values in combination with distribution provided in the scatterplots 
suggest that other factors beyond vulnerability play a significant role in the allocation of Germany's bilateral adaptation assistance.

\subsection{Expert Interviews: Finance Allocation Factors beyond Vulnerability from a Donor Perspective}

The findings show that from the perspective of a key donor country other factors beyond vulnerability have great relevance for the attribution and prioritization of international adaptation finance. The analysis here confirmed the findings of previous studies (cf. $[44,56,60])$ that the logic of allocating bilateral adaptation assistance by Germany is largely in line with that of traditional bilateral development cooperation. Factors largely corresponded to considerations of recipient need, recipient merit, and donor interest as highlighted in previous models on traditional development aid allocation (see Section 3.1 and Table 3 below). Yet, the explorative approach of the study and the data collected in the expert interviews also allows to identify factors beyond these three models. In particular, there are indications of an emerging cluster of factors around perceived "recipient interest."

Table 3. Factors beyond vulnerability shaping adaptation finance allocation from a donor perspective.

\begin{tabular}{|c|c|c|c|}
\hline \multicolumn{3}{|c|}{ Previous Aid Allocation Models } & \multirow{2}{*}{$\begin{array}{l}\text { Additional Model } \\
\text { Recipient Interest }\end{array}$} \\
\hline Recipient Need & Recipient Merit & Donor Interest & \\
\hline $\begin{array}{l}\text { Vulnerability } \\
\text { Human } \\
\text { Development Index }\end{array}$ & $\begin{array}{l}\text { Institutional capacity to } \\
\text { manage resources } \\
\text { Accountability } \\
\text { Sustainability } \\
\text { Absence of a conducive } \\
\text { situation in the country }\end{array}$ & $\begin{array}{l}\text { Political priorities } \\
\text { Behaviour of other } \\
\text { donors } \\
\text { Diplomatic relations }\end{array}$ & $\begin{array}{l}\text { Country ownership } \\
\text { Role in climate } \\
\text { negotiations }\end{array}$ \\
\hline
\end{tabular}

The interviewees stressed factors corresponding to the perceived recipient need, including in particular, vulnerability and the Human Development Index (HDI) of the country. While vulnerability indices such as ND-GAIN, Germanwatch's Climate Risk Index, and Maplecroft were mentioned as being consulted, experts shared the same challenge as discussed in the literature: every index presents slightly different results, thereby making it difficult to prioritize along them. Rather than the country level, experts shared that vulnerability analyses at the local level played an important role in the selection of projects.

Related to the model of recipient merit, interviewees from key institutions within Germany emphasized four key factors that play a role. First, experts shared that the challenge was not only that there were not enough resources for vulnerable countries, but also the recipient country's institutional capacity to manage the resources- "Can the country actually absorb the support that we can provide?" (Germany-International Organization-1, G-IO-1). As a response to this challenge, one expert stated that the most vulnerable countries, which are often LDCs, are supported with different financial instruments for adaptation than other countries, i.e., they primarily receive grants. However, middle-income countries would rather receive funding in terms of loans, thereby adding the country's ability to pay back a loan as a consideration to the decision-making process (Germany-Civil Society Organization-1, G-CSO-1). Second, the allocation of support for adaptation is guided by the overarching concern of accountability, and this in turn calls for two capacities on the side of the recipient country: the capacities to develop project proposals and to efficiently implement projects (G-IO-1, G-IO-2, G-CSO-1). Examples of concrete capacities referred to the ability to develop fundable, feasible, sustainable, and adaptation-relevant proposals (Germany-Ministry-1, G-MIN-1, G-MIN-3, G-IO-1). Third, in addition to capacity concerns, the sustainability of the project in terms of the possibility of the project being continued by the country with its resources was also stressed as an important factor (G-IO-1). Highlighting the importance of good project proposals for future funding, one expert added that successful projects could generate a multiplier effect, i.e., have an increased opportunity to get access to additional German or co-financed funding in the future. Fourth, a constraining factor indicated by the experts is the absence of a conducive situation in the country for executing a project because of the 
lack of political stability, crisis, disease or disaster, or the lack of a culture of cooperation and solidarity (G-IO-1). The latter example refers to sectoral thinking in societies among ministries, academia, and implementing organizations because such silo activities impede the ideal of collectively reflecting and working on a cross-cutting issue like adaptation. (G-MIN-2).

Corresponding to the model of donor interest, the findings here show three key factors that play a role. These factors include political priorities, behavior of other donors, and diplomatic relations, and are classified under "positive" and "negative" motivations (G-MIN-1, G-MIN-2, G-IO-1). As an example of political priorities as a positive motivation, one expert shared that if high-ranking dignitaries of Germany emphasized the importance of cooperation with a particular country and called for increasing the support to this country, this could result in a reallocation of resources. The presence of other donors could act as a positive or negative motivation, and this was argued to ensure that Germany had an "added value" to make, in the interest of a "division of labor." On the other hand, a negative motivation could be diplomatic disputes or tensions with a country that could result in a cut of resources, even if it would be an otherwise important partner country for climate change.

The bottom-up approach of the study allowed us to identify and explore another cluster of factors that played a role in the allocation of adaptation finance in relation to perceived recipient interest. The interview data suggests two key factors used to gauge the recipient country's interest and commitment to adaptation-country ownership and its role in climate negotiations. First, country ownership means an agreement in the donor's priority areas, specifically the recipient country's willingness, interest, and seriousness regarding adaptation investment. It also includes the recipient country's political priorities, domestic climate policies, and commitment to climate change adaptation. A country's commitment to climate change adaptation is manifested in several ways, including political papers published by the government, a link of the activities related to Nationally Determined Contributions (NDCs) and relevant to climate change adaptation and political leadership (G-MIN-2, G-IO-1). Second, the role of the country in climate change negotiations (such as in the Conference of the Parties or Subsidiary Body of Scientific and Technological Advice (SBSTA) Meetings of UNFCCC) is also being observed, i.e., if the country is playing a constructive role and contributes to bringing about global action on climate change - or whether it is rather opposed to the process, deconstructive, and slowing down action by actively preventing the discussion to move forward (G-IO-1).

Referring specifically to India-a focus of this paper-experts highlighted that the country is considered to be an important partner for climate change support not only because of its climate change impacts but also because of its importance in the global agenda of climate change. India was stressed to be an emerging economy, having a proper administration and high global political and economic importance. Many of the factors mentioned for the global allocation considerations were found to apply to the bilateral allocation of adaptation finance to India, as well. However, expert interviews revealed two key factors that play a role in the case of India in particular, and were not explicitly mentioned in the general case of bilateral support to adaptation. First, cost-benefit analyses plays an important role in the decision on the final amount that was allocated because India is primarily supported with reduced interest loans. Hence, it was laid out that supported projects should generate an additional income for India to be able to pay back the loan to Germany. Second, experts mentioned that they faced a principal-agent problem, whereby, even though being in Germany with only a rough understanding of technical linkages and in consideration of political and economic priorities and pressures, they had to make targeted investments. Reiterating the accountability concern mentioned above, one interviewed expert mentioned that there is some pressure on them to produce "ambitious, visible, and easy to communicate results—something that flies. Because we are using German taxpayers' money." There is also a certain technical knowledge and information gap on what is happening on the ground, which is difficult to bridge. In this regard, interviewees mentioned that a high turnover rate in India, especially in leadership positions, make it difficult to quickly and easily establish a relationship based on trust. However, a positive example that was cited is the relationship with the National Bank for Agriculture 
and Rural Development (NABARD). This relationship, based on trust and confidence in NABARD's fiduciary standards, played an important role in bilateral cooperation with India.

On allocation to multilateral funding, experts interviewed could not comment on the details. This was because decisions on the allocations to these funds were taken by high-level officials.

\subsection{Expert Interviews: Finance Access Factors beyond Vulnerability from a Recipient Perspective}

This part of the analysis focuses on understanding the factors that play a role in the access to adaptation finance from a recipient perspective (Q5). Overall, the interview data does not identify vulnerability to be an important factor in attracting adaptation finance. Vulnerability, on the contrary, was suggested to often play a constraining role for two reasons. First, it imposes capacity challenges on project applicants, who are required to prove the vulnerability of a region through data and vulnerability assessments. Second, particularly in the case of accessing multilateral funds, one expert claimed to see India as disadvantaged in the competitive process as the country is "higher up in the order" (meaning less vulnerable than other countries) compared to LDCs, SIDS, and African nations, which naturally receive "more support and sympathy" (India-Executing Entity-3, I-EE-3). Beyond vulnerability, the analysis identified five key enabling factors and two key constraining factors that were considered to play a key role in the access to adaptation finance.

Among the five enabling factors, the most emphasized and reiterated factor was the crucial role of the National Bank for Agricultural and Rural Development (NABARD), one of the main nodal agencies in India for accessing adaptation finance. One interviewee phrased his admiration as follows: "Thank God we have NABARD ... it has those systems to churn out things faster" (India-International Organization-2, I-IO-2). Being a Development Finance Institution, it fits many criteria that were required in an international partnership, such as access funding, strict fiduciary standards, rigorous rules and regulations, compliance with high environmental and social standards, transparency, gender policy, etc. These criteria were mentioned to favorably distinguish NABARD from other organizations such as NGOs, which may lack the capacity, for example, to manage complex financial modalities such as loans and 'blended' projects. Flexibility in recruitment policies and responsiveness to adopting best practices and processes from abroad were also mentioned as factors that potentially play a role (India-National Implementing Entity-1, I-NIE-1, I-IO-2). NABARD became an important delivery partner because of its extensive presence, with offices at district and regional levels. This further contributes to a good working relationship with all state governments. NABARD also had a vast network, with 5600 partners including cooperatives, regional, commercial, and rural banks (I-NIE-2). Interviewees shared their perceptions that this extensive network is essential in attracting bilateral agencies to collaborate with NABARD because of the potential for increasing the impact of funding.

NABARD also plays a crucial role in the pre-selection and review of projects before submission to multilateral funds, as its criteria aimed to reflect those of the selection process by the funds. According to the interview data, the most important criteria NABARD checked for was whether the projects "follow the grammar of adaptation projects ... risk, vulnerability" (I-NIE-1).

Second, quality and relevance of the project proposals are considered an important enabling factor. For example, considerations included a clear distinction between "adaptation and business as usual," vulnerability assessments, alignment to the National Action Plan for Climate Change (NAPCC) and the State Action Plan for Climate Change (SAPCC) priorities, the urgency of action, transformational impact, scaling-up opportunities, capacity to identify geographic hotspots, stakeholder consultation, and community involvement.

The third enabling factor refers to political aspects such as timing, support from local and state governments, and high-level political attention in the initial stage of project selection and formulation. Political priorities indicated in the national and state action plans on climate change as well as the government's financial investment of over USD 50 million were seen as strong indicators of domestic commitment to adaptation. 
The fourth and fifth success factors were drawn from interviews with project implementers and other civil society actors who were successful in accessing adaptation funding through both bilateral as well as multilateral channels. A common factor and need that was mentioned as underlying the success of all projects was the role of past projects and experience. NGO representatives from India highlighted the importance of spending time and earning the trust and willingness of community members to participate and hence, ensuring the success of a project. Therefore, these interviewees suggested the need for a programmatic funding cycle. Experts also noted the importance of their own previous experience in working with international agencies such as UNDP, World Bank, and the German Corporation for International Cooperation (GIZ) to better understand the process of project development. Emphasizing the lack of project proposal writing skills, they also acknowledged the role of consultants from DFID and USAID in "fine-tuning" the proposal.

Finally, previous bilateral support was seen as an important success factor. Experts shared that not only did it have the advantage of having earned the commitment and trust of communities (which played a big role in the success of the implementation) but it also acted as an incubator for attracting scaled-up multilateral project funds. The project proposals benefited from data collection and vulnerability assessments already completed with the help of bilateral funding.

Despite having succeeded in accessing funding, experts shared two key constraining factors they faced while applying for support. First, at the domestic level, there was a lack of technical capacity in project development. This included difficulties in defining the concreteness and cost-effectiveness of adaptation. An additional struggle was navigating the bureaucracy of the application process. Examples of specific capacities for project development included data collection, distinguishing between adaptation and development projects, modelling and assessments of future risks to which countries wish to adapt, knowledge of available sources, channels and processes in the adaptation finance architecture (I-IO-2, India-Executive Entity-1, I-EE-1). An important constraint mentioned is the lack of capacity to conduct vulnerability assessments to support their claims of the vulnerability of a region (I-IO-1). Second, at the national level, experts shared the challenge of a silo culture among the ministries and a lack of transparency in decision-making (I-IO-1, India-Civil Society Organization-1, I-CSO-1,). Overall, experts reflected that the challenge was that, on the one hand, the high fiduciary standards and other capacity requirements made it difficult for vulnerable countries to access climate finance. However, on the other hand, the experts affirmed the importance of these quality criteria to ensure the efficient use of the money. Hence, it was important to maintain a check on the "standards to see if they are too bureaucratic ... or slowing down progress without giving anyone benefits" (I-CSO-1).

In reference specifically to Germany-the other empirical focus of this paper-experts highlighted the importance of bilateral relations with Germany to receive adaptation funding. India has had a longstanding bilateral development cooperation relationship with Germany for over 60 years. This contributed to building trust, a growing sense of familiarity in working style, and management of expectations on both sides, thus positively influencing the receipt of adaptation support over the past years (I-NIE-1,I-IO-2). India's requests for bilateral support were primarily driven by the desires for meeting their NDC targets (ibid.). Experts shared that matchmaking of priority areas and willingness to commit to climate change adaptation at the national and sub-national level played a role. These were manifested as well as enabled through the country's National and State level action plans on climate change (NAPCC and SAPCC, respectively). Germany primarily provided bilateral support to India in terms of reduced interest loans through its development bank KfW (Kreditanstalt für Wiederaufbau). Hence, in order to engage in financial cooperation with Germany, experts underscored the importance of NABARD, a strong Development Finance Institution (DFI), in receiving and managing funding (I-NIE-1, I-NIE-2). 


\section{Conclusions}

International adaptation finance plays a major-and increasing-role in addressing the consequences of climate change. In considering the distribution and allocation of such finance, the international community has agreed on a normative and political level to prioritize countries with high vulnerability. In a first step, this study therefore asked whether this prioritization of the most vulnerable countries can be observed in recent adaptation assistance allocation. Analyzing this question was met with challenges in relation to the definition and operationalization of vulnerability, as well as the reliability of data on adaptation assistance. At the same time, the distribution of adaptation finance might depend not only on the perceived levels of vulnerability but also on other factors. Hence, the study aimed, in a second step, to understand which other enabling and constraining factors play a role in donor countries' allocations and recipient countries' access to adaptation finance. Adopting a mixed-methods research design, the paper drew on two levels of analysis. On the global level, it showed the correlation between vulnerability levels and bilateral adaptation assistance flows, pre- and post-Paris Agreement. On the national level, it conducted a similar correlation for Germany's bilateral commitments to adaptation. Drawing on qualitative interview data, the paper then explored additional enabling and constraining factors regarding the allocation of and access to adaptation finance from donor and recipient perspectives.

The results of this study must be analyzed in view of its limitations. Methodologically, the quantitative analysis faced the challenge of using the Rio Marker adaptation finance database despite concerns about its methodology as raised in previous literature (cf. Section 2). However, we used this database because of its advantage of allowing comparability on a global level and its wide use in previous studies. Operationalizing vulnerability has its scientific challenges, as described in Sections 2 and 3. However, given the significant role that global vulnerability metrics play in international policy forums and debates, we used mean vulnerability scores of countries across the three leading global risk indices (cf. Section 2). The qualitative data drew on a rather small sample size of interviews $(n=19)$. Nevertheless, interviewed experts included high-level officials and decision-makers in ministries, as well as international organizations. Moreover, accessibility to this level of experts was limited. Yet the information collected from experts should also be seen in light of the challenges around "methodological individualism," bearing in mind that they are individuals and do not necessarily represent the full spectrum of views in the organizations to which they are affiliated [61]. Despite these limitations, the study contributes important empirical insights to an emerging frontier of research and it has noteworthy findings to contribute on the five questions that guided the analysis (Section 1).

The results of a literature analysis in response to the first question (Q1) (cf. Section 3.1) showed that past models of explaining development aid allocation might also be useful for the assessment of the factors shaping the allocation of bilateral adaptation finance. Factors highlighted in these models might include the (perceived) level of a country's vulnerability but also touch on various other dimensions related to recipient need, donor interest, and recipient merit. Yet, comprehensive studies applying such factors to the case of adaptation finance allocation do not yet exist, despite emerging indications in previous studies that adaptation allocation does not solely follow vulnerability considerations.

Our results of the global-scale allocation analysis in response to the second question (Q2) (cf. Section 3.2) showed that there was only a weak correlation between the distribution of bilateral adaptation assistance and the vulnerability of receiving countries, as measured by standard vulnerability metrics. This weak correlation held true for both pre- and post-Paris Agreement periods, even though the political goal of prioritizing adaptation finance to the most vulnerable countries has been around for a long time and was re-confirmed by the international community within the Paris Agreement. From a donor perspective, our analysis showed that the relationship between vulnerability and bilateral adaptation finance was also weak in the allocation contributed by Germany, one of the largest donors in this field globally (Q3) (cf. Section 3.3). Hence, both sets of correlation analyses suggest that factors beyond vulnerability play a prominent—maybe primary-role in the allocation of adaptation finance. 
The results in response to the fourth question (Q4) (cf. Section 3.4) revealed factors beyond vulnerability that played a role in the allocation of Germany's bilateral adaptation finance. These factors largely corresponded to the factors discussed in traditional development aid allocation models in relation to recipient need, donor interest, and recipient merit. They include, in particular, HDI, institutional capacity to manage resources, accountability, sustainability, absence of a conducive situation in the country, political priorities, behavior of other donors and diplomatic relations. Yet an additionally emerging cluster of factors can be observed beyond the ones considered in previous development aid models, that is, recipient interest in climate change, signaled through country ownership and role in climate negotiations. In response to the last question, addressing access factors from a recipient perspective (Q5) (cf. Section 3.5), the results on India revealed that important enabling factors for attracting adaptation funding include the crucial role of NABARD, quality and relevance of the project proposals, political aspects, role of past projects and experience, and previous bilateral support. In addition, two constraining factors were highlighted: lack of technical capacity in project development and a silo culture and lack of transparency in decision-making.

These findings present several implications for future climate policy. They point to the operational and political challenges that the narrative of the vulnerability-oriented prioritization of adaptation finance presents. It seems that in reality the institutional capacity and bureaucratic fitness to absorb and use adaptation funds according to donor quality standards still play a significant role. It is important to point out that all countries are vulnerable to the impacts of climate change in one way or the other. Hence, in light of the fact that the most vulnerable countries, according to the index-based ranking, are not receiving the highest amounts of funding, building institutional capacities in developing countries would play a significant role in allocating funding to them. The findings, therefore, call for improvement of the climate finance readiness of institutions at the national and sub-national levels of the most vulnerable countries. However, eventually the findings raise the vexing question of how to achieve the difficult balance between meeting donors' requirements of high fiduciary standards and project management capacities on the one hand, and increasing the access of the most vulnerable countries who may lack the resources and institutional capacities to implement climate finance projects. While donor interests certainly have their legitimacy, the troubling question is whether their translation into the current adaptation finance infrastructure will guarantee that no country is left behind in being supported in its adaptation efforts, particularly not the most vulnerable ones.

Author Contributions: D.D. and M.G. jointly conceived the paper as well as the methodology for its underlying analysis. D.D. conducted the correlation analysis and expert interviews. D.D. and M.G. jointly analyzed the data and drafted the paper. All authors have read and agreed to the published version of the manuscript.

Funding: This research received no external funding.

Acknowledgments: The authors would like to thank the anonymous reviewers for their constructive comments which helped to improve the paper. We also would like to thank the interviewed experts for sharing their valuable insights and perspectives.

Conflicts of Interest: The authors declare no conflict of interest. 


\section{Appendix A}

Table A1. Information on the expert interviews.

\begin{tabular}{cc}
\hline Code & Type of Organization \\
\hline & GERMANY \\
G-MIN & Ministry at the Federal level \\
G-IO & International development organization \\
G-CSO & Civil Society Organization \\
& INDIA \\
I-IO & International development organization \\
I-MIN & Ministry at the Federal level \\
I-NIE & National Implementing Entity \\
I-AA & Academic actor \\
I-EE & Executing Entity from civil society \\
I-CSO & Civil Society Organization \\
\hline
\end{tabular}

\section{References}

1. UNFCCC. FCCC/CP/2015, "Adoption of the Paris Agreement". In Proceedings of the Conference of the Parties 21st Session, Paris, France, 30 November-11 December 2015.

2. Puig, D.; Olhoff, A.; Bee, S.; Dickson, B.; Alverson, K. The Adaptation Finance Gap Report; United Nations Environment Programme: Nairobi, Kenya, 2016.

3. Harmeling, S.; Kaloga, A.O. Understanding the Political Economy of the Adaptation Fund. IDS Bull. 2011, 42, 23-32. [CrossRef]

4. Klein, R.J.; Möhner, A. The Political Dimension of Vulnerability: Implications for the Green Climate Fund. IDS Bull. 2011, 42, 15-22. [CrossRef]

5. Pelling, M.; Garschagen, M. Put equity first in climate adaptation. Nature 2019, 569, 327-329. [CrossRef] [PubMed]

6. UNFCCC. United Nations Framework Convention on Climate Change; FCCC/INFORMAL/84 GE.05-62220 (E) 200705; United Nations: Rio de Janeiro, Brazil, 1992.

7. UNFCCC. Report of the Conference of the Parties on Its Fifteenth Session; Held in Copenhagen from 7 to 19 December 2009; United Nations Framework Convention on Climate Change: Copenhagen, Denmark, 2009.

8. Persson, Å.; Klein, R.J.; Siebert, C.K.; Atteridge, A.; Müller, B.; Hoffmaister, J.; Lazarus, M.; Takama, T. Adaptation Finance under a Copenhagen Agreed Outcome; Stockholm Environment Institute: Stockholm, Sweden, 2009.

9. UNFCCC. Framework Convention on Climate Change of the Parties to the Kyoto Protocol. In Proceedings of the Conference of the Parties Serving as the Meeting of the Parties to the Kyoto Protocol on Its Sixth Session, Cancun, Mexico, 29 November 2011; pp. 1-32.

10. OECD. Climate Finance Provided and Mobilised by Developed Countries in 2013-17; OECD Publishing: Paris, France, 2019. [CrossRef]

11. OECD. Climate Related Development Finance: InteractiveWorkbook. 2015. Available online: https://public.tableau.com/views/Climate-relateddevelopmentfinance-RP/CRDF-Recipient?:embed=y\&: display_count=no\&\%3AshowVizHome=no\#3 (accessed on 3 April 2018).

12. Saunders, N. Climate Change Adaptation Finance: Are the Most Vulnerable Nations Prioritised? Stockholm Environment Institute: Stockholm, Sweden, 2019.

13. Ayers, J.M.; Abeysinghe, A.C. International Aid and Adaptation to Climate Change. In The Handbook of Global Climate and Environment Policy; Wiley Blackwell: Oxford, UK, 2013; pp. 486-506.

14. Weikmans, R. Towards transparency: The 2016 Adaptation Finance Transparency Gap Report; Adaptation Watch, 2016; Available online: http://www.adaptationwatch.org/\#about (accessed on 19 May 2020).

15. Donner, S.D.; Kandlikar, M.; Webber, S. Measuring and Tracking the Flow of Climate Change Adaptation Aid to the Developing World in Environmental Research Letters; IOP Publishing Limited: Bristol, UK, 2016; Volume 11, Number 5.

16. Garschagen, M.; Doshi, D. Global adaptation finance does not reach many of the most vulnerable countries. Submitted, under review. 
17. Eckstein, D.; Künzel, V.; Schäfer, L.; Winges, M. Global Climate Risk Index 2020 Who Suffers Most from Extreme Weather Events; Germanwatch: Bonn, Germany, 2019.

18. UNFCCC. Parties/UNFCCC. Available online: https://unfccc.int/process/parties-non-party-stakeholders/ parties-convention-and-observer-states (accessed on 21 April 2020).

19. OECD. OECD DAC Rio Markers for Climate Handbook; OECD Publishing: Paris, France, 2016.

20. OECD. Creditor Reporting System (CRS). Available online: https://stats.oecd.org/Index.aspx?datasetcode= CRS1 (accessed on 3 April 2020).

21. Nakhooda, S.; Watson, C.; Schalatek, L. The Global Climate Finance Architecture. In Climate Finance Fundamentals; Overseas Development Institute and Heinrich Böll Stiftung: Washington, DC, USA, 2015.

22. Roberts, J.T.; Starr, K.; Jones, T.; Abdel-Fattah, D. The Reality of Official Climate Aid; Oxford Institute for Energy Studies: Oxford, UK, 2008.

23. Michaelowa, A.; Michaelowa, K.; Michaelowa, A.; Michaelowa, K. Coding Error or Statistical Embellishment? The Political Economy of Reporting Climate Aid. World Dev. 2011, 39, 2010-2020. [CrossRef]

24. Junghans, L.; Harmeling, S. Different Tales from Different Countries; Germanwatch: Bonn, Germany, 2012.

25. Weikmans, R.; Roberts, J.T. The international climate finance accounting muddle: Is there hope on the horizon? Clim. Dev. 2017, 11, 97-111. [CrossRef]

26. Garschagen, M.; Hagenlocher, M.; Comes, M.; Dubbert, M.; Sabelfeld, R.; Lee, Y.J.; Grunewald, L.; Lanzendörfer, M.; Mucke, P.; Neuschäfer, O.; et al. World Risk Report 2016 Focus: Logistics and Infrastructure; Bündnis Entwicklung Hilft and United Nations University EHS: Bonn, Germany, 2016.

27. Chen, C. University of Notre Dame Global Adaptation Index Country Index Technical Report. 2015. Available online: https://gain.nd.edu/assets/254377/nd_gain_technical_document_2015.pdf (accessed on 31 March 2020).

28. Vernaccini, M.; Poljansek, L. INFORM Index for Risk Management Concept and Methodology Version 2017; Publications office of the European Union: Luxembourg, 2017.

29. Hinkel, J. "Indicators of vulnerability and adaptive capacity": Towards a clarification of the science-policy interface. Glob. Environ. Chang. 2011, 21, 198-208. [CrossRef]

30. Birkmann, J.; Cardona, O.D.; Carreño, M.L.; Barbat, A.H.; Pelling, M.; Schneiderbauer, S.; Kienberger, S.; Keiler, M.; Alexander, D.; Zeil, P.; et al. Framing vulnerability, risk and societal responses: The MOVE framework. Nat. Hazards 2013, 67, 193-211. [CrossRef]

31. Datenbank Deutsche Klimafinanzierung. Available online: https://datenbank.deutscheklimafinanzierung.de/ (accessed on 2 April 2020).

32. Bernard, H. Research Methods in Anthropology, 4th ed.; AltaMira Press, Rowman and Littlefield Publishers: London, UK, 2006.

33. Glaser, B.G.; Strauss, A.L. The discovery of grounded theory. In New Brunswick and London; Aldine Transaction: New Brunswick, NJ, USA; London, UK, 1967.

34. Bernard, H. Russell: Social Research Methods. Qualitative and Quantitative Approaches; SAGE Publications Inc.: Washington, DC, USA, 2013.

35. Dudley, L.; Montmargquette, C. A Model of the Supply of Bilateral Foreign Aid. Am. Econ. Rev. 1976, 66, 132-142.

36. Maizels, A.; Nissanke, M.K.; Maizels, A.; Nissanke, M.K. Motivations for aid to developing countries. World Dev. 1984, 12, 879-900. [CrossRef]

37. McKinlay, R.D.; Little, R. A Foreign Policy Model of U.S. Bilateral Aid Allocation. World Politi. 1977, 30, 58-86. [CrossRef]

38. Berthelemy, J.-C. Bilateral Donors' Interest vs. Recipients' Development Motives in Aid Allocation: Do All Donors Behave the Same? Rev. Dev. Econ. 2006, 10, 179-194. [CrossRef]

39. Burnside, C.; Dollar, D. Aid, Policies, and Growth. Am. Econ. Rev. 2000, 90, 847-868. [CrossRef]

40. Lewis, T.L. Environmental Aid: Driven by Recipient Need or Donor Interests? Soc. Sci. Q. 2003, 84, $144-161$. [CrossRef]

41. Opršal, Z.; Harmáček, J. Is Foreign Aid Responsive to Environmental Needs and Performance of Developing Countries? Case Study of the Czech Republic. Sustainability 2019, 11, 401. [CrossRef]

42. Hicks, R.L.; Parks, B.C.; Roberts, J.T.; Tierney, M.J. Greening Aid? Understanding the Environmental Impact of Development Assistance; Oxford University Press: Oxford, UK, 2008. 
43. Figaj, M. Who gets environmental aid? The characteristics of global environmental aid distribution. Environ. Econ. Policy Stud. 2010, 12, 97-114. [CrossRef]

44. Betzold, C. Vulnerabilität, Demokratie, politische Interessen? Wie Deutschland seine Hilfe für Anpassung an den Klimawandel verteilt. Z. Int. Bezieh. 2015, 22, 75-101.

45. Betzold, C.; Weiler, F. Allocation of aid for adaptation to climate change: Do vulnerable countries receive more support? Int. Environ. Agreem. Politi. Law Econ. 2017, 17, 17-36. [CrossRef]

46. Weiler, F.; Klöck, C.; Dornan, M. Vulnerability, good governance, or donor interests? The allocation of aid for climate change adaptation. World Dev. 2018, 104, 65-77. [CrossRef]

47. Betzold, C.; Weiler, F. Aid for Adaptation to Climate Change in Germany, Sweden and the United Kingdom. In Innovations in Climate Governance; INOGOV: Norwich, UK, 2016.

48. Grasso, M. An ethical approach to climate adaptation finance. Glob. Environ. Chang. 2010, 20, 74-81. [CrossRef]

49. Fussel, H.-M. How inequitable is the global distribution of responsibility, capability, and vulnerability to climate change: A comprehensive indicator-based assessment. Glob. Environ. Chang. 2010, 20, 597-611. [CrossRef]

50. Bohle, H.-G. Vulnerability and criticality perspectives from social geography. IHDP Update 2001, 2, 1-7.

51. Parry, M.; Canziana, O.; Palutikof, J.; van der Linden, P.; Hanson, C. (Eds.) Contribution of Working Group II to the Fourth Assessment Report of the Intergovernmental Panel on Climate Change; Cambridge University Press: Cambridge, UK, 2007.

52. Turner, B.L.; Kasperson, R.E.; Matson, P.A.; McCarthy, J.J.; Corell, R.W.; Christensen, L.; Eckley, N.; Kasperson, J.X.; Luers, A.; Martello, M.L.; et al. A framework for vulnerability analysis in sustainability science. Proc. Natl. Acad. Sci. USA 2003, 100, 8074-8079. [CrossRef] [PubMed]

53. Khan, M. Toward a Binding Climate Change Adaptation Regime; Routledge: New York, NY, USA, 2013.

54. Barrett, S. Subnational Adaptation Finance Allocation: Comparing Decentralized and Devolved Political Institutions in Kenya. Glob. Environ. Politics 2015, 15, 118-139. [CrossRef]

55. Betzold, C.; Weiler, F. Development Aid and Adaptation to Climate Change in Developing Countries; Springer Science and Business Media LLC: Cham, Switzerland, 2018.

56. Robinson, S.-A.; Dornan, M. International financing for climate change adaptation in small island developing states. Reg. Environ. Chang. 2016, 17, 1103-1115. [CrossRef]

57. Robertsen, J.; Francken, N.; Molenaers, N. Determinants of the Flow of Bilateral Adaptation-Related Climate Change Financing to Sub-Saharan African Countries. SSRN Electron. J. 2015. [CrossRef]

58. Persson, Å.; Remling, E. Equity and efficiency in adaptation finance: Initial experiences of the Adaptation Fund. Clim. Policy 2014, 14, 488-506. [CrossRef]

59. Stadelmann, M.; Frisari, G.; Boyd, R.; Feás, J. The Role of Public Finance in CSP: Background and Approach to Measure its Effectiveness. Available online: https://core.ac.uk/download/pdf/53180262.pdf (accessed on 19 May 2020).

60. Betzold, C. Aid and Adaptation to Climate Change in Pacific Island Countries. SSRN Electron. J. 2016. [CrossRef]

61. Heath, J. Methodological Individualism. In Stanford Encyclopedia of Philosophy; The Metaphysics Research Lab: Stanford, CA, USA, 2015.

(C) 2020 by the authors. Licensee MDPI, Basel, Switzerland. This article is an open access article distributed under the terms and conditions of the Creative Commons Attribution (CC BY) license (http://creativecommons.org/licenses/by/4.0/). 